University Grants Committee to advise further on the choice of a location. He indicated that decision regarding the structure of Government would be taken within a weok or two, and in reply to questions on the following day regarding the recommendation for establishing six new universities, Mr. Hogg said the whole matter had been referred to the University Grants Committee. He also gave the figures for medical students registered at universities as follows: $1959,12,314 ; 1960,12,276 ; 1961$, 12,$254 ; 1962,12,550 ; 1963,12,890$.

In opening the debate in the House of Lords, Lord Silkin referred to the recognition in the White Paper on Industrial Training that the number of new entrants to skilled occupations was insufficient for Britain's future needs, and also to the importance of securing the right quality of teachers and teachers of the right status. The Earl of Dundee, who followed, for the Government, apart from a closer review of the Newsom Report, addod little to what Sir Edward Boyle had already said in the House of Commons. He pointed out that Britain's expenditure of $£ 414$ million on education in 1952 was just more than 3 per cent of her gross national product; $£ 804$ million in 1958-59 was 4 per cent; and the $£ 1,300$ million in the present year was 5 per cent of her gross national product. Later, the Earl of Bessborough referred to educational television, expressing the hope that this medium would be used to the maximum extent possible for educational purposes. He thought that ultimately it might be necessary for one or more channels to be devoted exclusively to education.

\title{
SCIENTIFIC RESEARCH IN SCHOOLS
}

$\mathrm{T}$ THE question of teachers in schools undertaking research in science brings together a number of considerations which are nicely poised. One primary fact is that any research with a successful outcome is a contribution to the total stock of human knowledge. But many teachers can be good instructors even if they have nothing to do with research, provided that they take the trouble to keep themselves informed of new developments. They are not all capable of worth-while independent enquiry, and the courses they pursued before graduation may have fallen short of making then, familiar with the spirit and techniques of experimental investigation. From this point of view the teachers most likely to succeed in research are those who after graduation stayed on for some time at the university, and then, perhaps finding prospects not up to expectations, took up appointments in schools. In the opposite direction, there is always a small movement of teachers who after a period of school experience return to university work.

Then there are different kinds of research which teachers can take up. Some are worth pursuing, although they do not carry enquiry very far; they can be 'pottered' with as occasions permit; they need not make any heavy demands on attention and may be looked on almost as a recreation. A.t the other extreme are research problems which take a big slice of a teacher's free time and mental energy. Indeed, it does not necessarily follow that a man who is competent at research is a good instructor, well versed in all sections of the sixth-form syllabus which ho is required to teach. The project which he is pursuing may have scarcely any relation to his school work. Again, in so far as research constitutes an important element in his life, it may draw him away from the corporate life of the school, lower his social standing among members of the local community and debar him from higher educa- tional posts. Typically, what he can hope for is to become head of his own department.

Among considerations of this nature the point of equipoise is slowly shifting, and mainly through help from the Royal Society an increasing number of science teachers are carrying out research. In 1957, taking the view that "the teaching of science in schools might be improved if those engaged in it were enabled to carry out some research work of their own choice, preferably involving participation by pupils", the Society set up a Scientific Research in Schools Committee. This Committee invites proposals from any teacher about a research project which he or she would like to carry out. If this meets with approval, the Committee appoints a suitable adviserusually a Fellow of the Society or a senior member of a university department-with whom the teacher can keep in contact. The Committee is also prepared to consider applications for grants for the purchase of such materials and apparatus as may be required.

The sixth annual report of the Committee, which was issued in November 1963, shows that 84 science teachers were carrying out research with the help of the Royal Society, and that six original papers had, during 1963 , been published. However, figures received more recently from the Royal Society indicate that by mid-January 1964, 94 science teachers are now participating in the scheme. The təachers concerned hold appointments in a wide range of schools: Secondary Modern, 4; Secondary Grammar, 42; Public and Private, 34; and others, 5. The spread of the subjects covered was: biology, 43; chemistry, 24; crystallography, 2; engineering, 1; geology, 6; physics, 14; radio-astronomy, 3 ; and time and motion study, 1. The grants supplied by the Royal Society for these projects totalled $£ 619$ in $1957-58$, while the figure for the year $1962-63$ was $£ 4,450$.

\section{THE BRITISH ANTARCTIC SURVEY}

$\mathrm{T}$ HE British Antarctic Survey Bulletin* is intended to supplement the existing series of monographs, the British Antarctic Survey Scientific Reports, by providing a channel of publications for preliminary reports, short notes and papers including some which are not specifically scientific. The Bulletin, which is being edited by Dr. R. J. Adio and Miss E. Todd, will be published as necessary to cope with the flow of papers, probably two or three times each year.

The first two issues, June 1963 (pp. 54) and December 1963 (pp. 96), show that these objectives are being met.

\footnotetext{
- British Antarctic Survey. Bulletin, No. 1; June 1963. Pp. 1-54. (London: British Antarctic Survey, 1963.) 10s. net.
}

These issues contain four papers on biological subjects, three on glaciology, two on meteorology, two on geophysical surveys and one on geomorphology. "The Human Element in Polar Exploration", by Sir Vivian Fuchs, and the longest paper of 25 pages on "Polar Ships and Navigation in the Antarctic", by J. P. Morley, are more general papers of considerable interest. Summaries of four recent "British Antarctic Survey Scientific Reports" are given in the first issue, and the foreword indicates that correspondenco concerning papers may appear in the future.

The Bulletin is printed on art paper and is copiously illustrated by photographs, maps, line drawings, etc. The quality and interest of the scientific papers are similar to 